\title{
Transformando los espacios de lectura. Una perspectiva crítica e inclusiva de las prácticas lectoras contemporáneas
}

\author{
Transforming Reading Spaces. A Critical and Inclusive Perspective of Contemporary \\ Reading Practices
}

\section{Transformando os espacios de lectura. Uma perspectiva crítica e inclusiva das práticas de leitura contemporâneas}

\author{
Aldo Ocampo-González \\ Centro de Estudios Latinoamericanos de Educación Inclusiva \\ Santiago, Chile \\ aldo.ocampo.gonzalez@gmail.com \\ https://orcid.org/0000-0002-6654-8269 \\ Concepción López-Andrada \\ Centro de Estudios Latinoamericanos de Educación Inclusiva \\ Santiago, Chile \\ clopezc@unex.es \\ https://orcid.org/0000-0002-9423-0434
}

Recibido • Received • Recebido: 04 / 09 / 2018

Corregido • Revised • Revisado: 28 / 07 / 2019

Aceptado • Accepted • Aprovado: 29/ $10 / 2019$

\begin{abstract}
Resumen: El presente trabajo examina la lectura como praxis político-cultural, en tanto condición de la justicia educativa y elemento constitutivo de la ciudadanía emancipatoria. La opción analítica que se presenta intenta, por un lado, reflexionar críticamente sobre las contrariedades intelectuales a las que se adscriben las tendencias en educación lectora y la construcción de justicia educativa y; por otro lado, demostrar las formas de cristalización de un campo sustentado en políticas difusas, de tal modo que un aspecto crucial radica en exponer la ambigüedad del universo conceptual empleado en este campo, cuyas repercusiones ofrecen falsas salidas. El estudio de la lectura como práctica cultural y social reclama una ecología de saberes, esto es, la creación de sistemas intelectuales que ofrezcan la posibilidad de garantizar alternativas viables para redistribuir el derecho a la educación y a la lectura, con justicia y, ante todo, acorde con lo que cada persona y grupo social requiere. Para promover cualquier tipo de transformación en la forma de redistribuir derechos, se observa la necesidad de repolitizar la lectura como condición democrática. De tal forma que en las políticas públicas, en vez de construir condiciones de justicia, se diversifican los patrones de discriminación institucional. El concepto de ciudadanía lectora reafirma la necesidad de consolidar una representación cultural alternativa, esto es, proveer de instrumentos que permitan agilizar una discusión cultural politizada sobre aquello que vamos a entender como práctica lectora y sistemas de apropiación de esta en el mundo contemporáneo.
\end{abstract}

Palabras claves: Lectura; alfabetización; inclusión; diferencia; democratización de la educación; justicia social. 
doi: http://doi.org/10.15359/ree.24-1.11

URL: http://www.una.ac.cr/educare

CORREO: educare@una.cr

\begin{abstract}
This paper examines reading as a political-cultural praxis, both as a condition of educational justice and the constitutive element of emancipatory citizenship. The analytical option presented seeks, on one hand, to critically reflect on the intellectual setbacks to which the trends in reading education and the construction of educational justice are associated with; , on the other hand, to demonstrate the crystallization forms of a field pinned down by fuzzy policies, so that a crucial aspect lies within exposing the ambiguity of the conceptual universe used in this field, whose repercussions offers false outputs. The study of reading as a cultural and social practice demands an ecology of knowledge, that is, the creation of intellectual systems that offer the possibility of ensuring viable alternatives to redistribute the right to education and reading, with justice and above all, according to what each person and social group requires. To promote any kind of transformation in the way rights areredistributed, we observe the need to repoliticize reading as a democratic condition,so that in public policies, instead of building conditions of justice, the patterns of institutional discrimination are diversified. The concept of reading citizenship reaffirms the need to consolidate an alternative cultural representation, that is, to provide the instruments that allow expediting a politicized cultural discussion about what we will understand as reading practice and its appropriation systems in the contemporary world.
\end{abstract}

Keywords: Reading; literacy; inclusive; difference; Democratization of education; social justice.

Resumo: Este artigo examina a leitura como praxis político-cultural, como condição de justiça educacional e elemento constituinte da cidadania emancipatória. A opção analítica apresentada tenta, por um lado, refletir criticamente sobre contrariedades intelectuais presentes nas tendências em educacao na leitura e na construção da justiça educacional e, por outro lado, demonstrar formas de cristalização de um campo sustentado por políticas difusas, de tal forma que, um aspecto crucial está em expor a ambigüidade do universo conceitual utilizado neste campo, cujas repercussões oferecem falsas saídas. $\mathrm{O}$ estudo da leitura como uma prática cultural e social reclama por uma ecologia de saberes, isto é, a criação de sistemas intelectuais que oferecem a possibilidade de assegurar alternativas viáveis para redistribuir o direito à educação e a leitura, com justiça e acima de tudo, de acordo ao que cada pessoa e grupo social necessita. Para promover qualquer tipo de transformação na forma de redistribuir direitos, se observa a necessidade de repolitizar a leitura como uma condição democrática. De tal forma que, nas políticas públicas, ao invés de construir condições de justiça, os padrões de discriminação institucional são diversificados. O conceito de cidadania leitora reafirma a necessidade de consolidar uma representação cultural alternativa, ou seja, fornecer ferramentas que agilizem um debate cultural politizado sobre o que se entende como uma prática de leitura e sistemas de apropriação da mesma no mundo contemporâneo.

Palabras-chave: Lectura; alfabetização; Inclusão; Diferença; Democratização da educação; justicia social.

\title{
La lectura como metáfora de práctica cultural y construcción de justicia
}

La lectura emerge como un mecanismo intelectual sofisticado y poderoso que posibilita la expansión y el ejercicio de la ciudadanía crítica, y que posee la capacidad de activar las posibilidades emancipadoras de la consciencia crítica (hooks, 2017). Se vincula a la proliferación 
de nuevas formas de expresiones ciudadanas, específicamente de naturaleza micropolítica y performativa, articuladora de mecanismos de agenciamientos alternativos, en ocasiones, antagónicos y opuestos a los marcos de valores hegemónicos que sustentan las propuestas de educación lectora, fomento de la lectura y las prácticas de acceso a la cultura letrada hegemónica. Al respecto, de Sousa Santos (2010) insiste en que, "la tarea crítica a seguir no puede ser limitada a la generación de alternativas. De hecho, requiere un pensamiento alternativo de las alternativas" (p. 46), específicamente, en materia de educación lectora. Nos interesa, en este trabajo, reclamar nuevas modalidades de configuración de un pensamiento para pensar la lectura como práctica política, social y cultural.

Un pensamiento alternativo de las posibilidades sobre educación lectora y educación inclusiva reclama un nuevo paradigma que dé lugar a nuevas constelaciones de significados, a la emergencia de objetivos intelectuales acordes con la multiplicidad de diferencias y a la cristalización de elementos que permitan problematizar la lectura como proyecto políticocultural de resistencia. En suma, desafíos estructurales que solo podrán ser consagrados en la emergencia de una espacialidad otra, capaz de albergar dichas proposiciones. La emergencia de un terreno coherente con dichos propósitos articulará su tarea en torno a la ampliación simbólica de los sentidos y textualidades que convergen en torno a la noción de lectura. En definitiva, es un pensamiento que articula una de sus tareas críticas en la creación de acciones que permitan subvertir los efectos excluyentes de la cultura letrada de tipo hegemónica en la interioridad de las prácticas de escolarización. De modo que 'pensamiento alternativo de las alternativas'y 'educación inclusiva'se convierten en claves para movilizar nuevas racionalidades para practicar la enseñanza y la praxis ciudadana a través de la lectura y de un ethos redistributivo más amplio.

El estudio de la lectura como práctica sociocultural reclama una ecología de saberes, esto es, la creación de sistemas intelectuales que ofrezcan la posibilidad de garantizar alternativas viables para redistribuir el derecho a la educación y a la lectura, con justicia y, ante todo, acorde con lo que cada persona y grupo social requiere -énfasis (re)distributivo y significado complejo de igualdad y equidad-. Hablamos, entonces, de una totalidad concebida como universomosaico o singularidades múltiples. La ecología de saberes, noción clave en la epistemología del sur propuesta por de Sousa Santos (2009), visibiliza los medios de interacción entre diversos saberes que confluyen en el ensamblaje de esta propuesta, específicamente, a través de múltiples saberes y hebras de conectividad de diversa naturaleza.

La construcción de una agenda investigativa, política y epistemológica sobre pensamiento alternativo acerca de las alternativas en materia de educación lectora, inclusión, ciudadanía, acción política y redistribución enfrenta, como primer obstáculo, la identificación de saberes que posibilitan, o bien, restringen la articulación de una intervención crítica en la vida de cada persona lectora, en sus agencias, procesos de biografización y trayectorias, así como en la escuela y en la sociedad. 
doi: http://doi.org/10.15359/ree.24-1.11

URL: http://www.una.ac.cr/educare

CORREO: educare@una.cr

Este pensamiento reclama una pragmática epistemológica sobre derecho a la lectura, justificada por contribuciones e influencias de diversa naturaleza, tales como la experiencia de los grupos oprimidos, los estudios sobre feminismo y de la mujer, los estudios Queer, los estudios post-coloniales, decoloniales y de la subalternidad, etc. En resumen, recorridos genealógicos que modelan el campo de producción de la educación inclusiva.

La configuración de una política de educación lectora y de derecho a la lectura, sustentada a través de un pensamiento alternativo de las alternativas, sugiere la creación de categorías analíticas que apoyen dicha empresa. Coincidiendo con Apple (1986), si nuestra intención consiste en transformar el mundo, entonces, es necesario alterar el vocabulario disponible con el objeto de interpretar determinados fenómenos. En cierta medida, sostenemos que los marcos disciplinarios y discursos que confluyen en la organización de los estudios sobre lectura social tienden a reproducir mecanismos de esencialización a través de sus planteamientos, incurriendo, en ocasiones, en la confirmación del efecto multicategórico y en la división simbólica del mundo. Por todo ello, consideramos relevante disponer de nuevos escenarios de dialogicidad y criticismo sobre ciudadanía crítica, lectura, inclusión y justicia social. A efectos de tales propósitos, inscribimos nuestros posicionamientos epistémicos, teóricos, políticos y metodológicos en una concepción transformadora, esto es, que articula su tarea política por fuera del modelo societal dominante, y se interesa por la creación de nuevas espacialidades, la reinvención del saber y la proposición de nuevas categorías analíticas que permitan comprender la alfabetización más cercana de las agencias de la multiplicidad de colectivos que arriban a las estructuras de escolarización.

La creación de un universo simbólico coherente con tales demandas teóricometodológicas exige que atendamos, desde este trabajo, la crisis de representación que afecta los marcos conceptuales sobre los que se articula -de naturaleza diseminal y rizomática- el orden de producción de la lectura como praxis social. Por crisis de representación (de Mussy y Valderrama, 2009) entendemos el conjunto de sistemas intelectuales, mapas cognitivos y paradigmas en crisis y desgastados, que limitan la apertura de modalidades alternativas para visibilizar la tareas críticas y hermenéuticas de la lectura en clave inclusiva. En este marco de acción, la praxis de la lectura queda concebida en términos de acontecimiento (Deleuze, 1969; Esperón, 2014; Žižek, 2014), es decir, "algo que actúa en un hecho" (de Mussy y Valderrama, 2009, p. 43) o, en palabras de Žižek (2014), "un cambio del encuadre mismo a través del cual percibimos el mundo y nos vinculamos con éste" (p. 12). 
El estudio en torno a la lectura, entendida como práctica cultural' y como consumo cultural, ha sido abordado por estudios como los de Pierre Bourdieu y Roger Chartier². El sociólogo y el historiador parten de la reflexión sobre el "etnocentrismo de la lectura", que se entiende como la manera de leer hegemónica, como esa forma de leer "adecuada" coincidente con la propuesta académica -y los marcos de institucionalización del saber- e institución educativa. Por otro lado, hay que considerar el "efecto de legitimidad", concerniente a la consideración social de la lectura, que distingue entre lo que verdaderamente se lee, de lo que se representa como socialmente legítimo, o sea, lo que se "dice" que se lee (Silva, 2003). Asimismo, el acto lector implica que su desarrollo pueda llevarse a cabo completa o parcialmente, de forma lineal, vertical, continua o discontinua, fragmentada, rápida o lentamente, o como una lectura en voz alta o como lectura íntima y silenciosa (Gutiérrez, 2009). De igual forma, la lectura no es una práctica homogénea ni uniforme cuando se sitúa en un lugar y espacio social, además de que los mismos textos u obras pueden ser objeto de muy diversos usos e "investiduras" sociales, incluso, pueden considerarse antagónicas (Lahire, 2004).

A tal efecto, recurriendo a la noción de'metáfora'(Bourdieu, Chamboredon y Passeron, 1994; Lakoff y Johnson, 2009; Ricoeur, 2001), ofrecemos, en este trabajo, un examen crítico acerca de la lectura como praxis político-cultural, en tanto condición de justicia educativa y construcción de ciudadanía emancipatoria. Investigaciones como las de Ricoeur (2001) han conceptualizado la utilidad de las metáforas como dispositivos de ampliación de conceptos-con valor cognitivo en sí mismos-, que facilitan sus grados de inteligibilidad entre una palabra y otra. Para Black (1963), las metáforas como recurso de comprensión y construcción del conocimiento operan

\footnotetext{
${ }^{1}$ La lectura como práctica cultural orienta las relaciones que se establecen entre los materiales escritos, las formas de leer y los protocolos de lectura que amplían y posibilitan espacios para la apropiación de la cultura escrita (Chartier, 2002). De tal modo, la práctica cultural de la lectura se desarrolla en un espacio intersubjetivo, conformado históricamente, en el que los sujetos lectores comparten dispositivos, comportamientos, actitudes y significados culturales en torno al acto de leer. "El concepto de práctica cultural sirve de puente entre los recursos culturales y la evidencia observable de los actos de leer en cierto contexto", desde lo material y lo simbólico (Rockwell, 2001, p. 14).

${ }^{2}$ Traducción publicada en la Revista Sociedad y Economía, (4), 161-175 con el título de "La lectura: Una práctica cultural. Debate entre Pierre Bourdieu y Roger Chartier"que recoge el debate entre los dos pensadores originalmente transmitido por Radio France en septiembre de 1983 y publicado en Pratiques de la lecture. Paris, Rivages, 1985.

${ }^{3}$ En relación con este punto afirma Bourdieu en Silva (2003, p. 167): “Dicho de otra manera, hay una oposición social entre dos tipos de lectores: los lectores de esas cosas que no merecen ser leídas, y los otros lectores, los que practican la verdadera lectura, la lectura de lo «eterno», de lo «clásico», la lectura de ese tipo de textos que merecen ser conservados y recordados". Añadimos, sobre este punto, el completo trabajo metodológico de Bahloul (2002), en donde el autor realiza un estudio cualitativo de 1985 de las prácticas de los pocos sujetos lectores y sus espacios de socialización, al margen de la institución educativa en donde estas "lecturas precarias" se significan por esa lectura de folletos, periódicos o revistas considerados textos triviales alejados del canon académicos y, consecuentemente, no valorados por la cultura dominante ni por las encuestas sobre hábitos lectores.
} 
doi: http://doi.org/10.15359/ree.24-1.11

URL: http://www.una.ac.cr/educare

CORREO: educare@una.cr

mediante un conjunto de implicaciones y agrupaciones, explicitando un complejo sistema paralelo de implicancias que refieren o describen un determinado asunto u objetivo analítico. En tal caso, el estudio de la dimensión social, cultural y política de la lectura, en tanto praxis de transformación del mundo, solo puede ser interpretada en términos de dispositivo, es decir, su función estratégica se define a partir de la captura y la intersección de una amplia, extensa y rica multiplicidad de campos del conocimiento, conceptos, discursos, estrategias, objetos, métodos, teorías, sujetos e influencias. Forja un campo y un saber en permanente movimiento.

Es menester reconocer que el estudio de las condiciones de estructuración del derecho a la lectura-que devele sus condiciones intelectuales y políticas-, se sustenta sobre un conjunto de equívocos de interpretación y de estrategias de vagancia epistémica. A pesar de constituir un tema que atraviesa una amplia gama de objetivos críticos de la educación y de constituir un tópico reiterativo - de gran fuerza- en múltiples discursos políticos, se observa un cruce ininteligible de influencias y condiciones intelectuales que sustentan su matriz de configuración, más allá de códigos de ordenación (Foucault, 1973) -leyes, decretos, normativas- empleados como marcos teóricos para organizar su campo de lucha. Esto es un reflejo de las políticas del "todo vale".

El abordaje de las políticas educativas (Rizvi y Lingar, 2009; Taylor, Rizvi, Lingard y Henry, 1997) sociales y culturales, a juicio de Ocampo y López-Andrada (2019), desde una perspectiva de justicia social y cultural, promueven:

Un enfoque del derecho aplicado a los bienes culturales, desde una perspectiva de valor colectivo, enfatizando en una totalidad homogenizante que concibe las diferencias como eje de diferenciación social -agudizando las condiciones de opresión, dominación e injusticia-, implantando una concepción del derecho a la lectura en bloque, cuya racionalidad restringe el potencial de la redistribución y la diferencia. (p. 87)

El problema ontológico de los grupos sociales, descrito por Young (2002), cristaliza un sistema de alteridad acrítica, restringida y absoluta al interior de las políticas públicas en materia de justicia social y educación, dando paso a un enfoque de asimilación arbitraria, sustentado en prácticas de absorción de lo minoritario y devaluación de las diferencias, preferentemente. Por esta razón, apostamos "por un enfoque relacional que reconoce la existencia de diferentes grupos sociales atravesados por variables de desigualdad múltiple (Hill Collins, 1990); al tiempo que otros colectivos son privilegiados en determinados contextos y pautas de culturización y experiencias de socialización" (Ocampo y López-Andrada, 2019, p. 88).

Retomando la obra de Brah (2011), analizamos, especialmente, las (re)articulaciones metodológicas y a qué refieren. 
Las múltiples modalidades del poder a través del ejercicio de la lectura y, en particular, de la cultura letrada hegemónica. En este sentido, el estudio de la dimensión social y política de la lectura se convierte en una forma de pensar en y a través de la subjetividad, el poder y las transformaciones sociales. Así como, al tipo de prácticas de lecturas que son sancionadas en la escuela. (Ocampo y López-Andrada, 2019, p. 88)

¿Por qué abordar e investigar relacionalmente el derecho a la lectura, a la información y a la cultura?, ¿qué incidencias metodológicas y repercusiones políticas entran en contacto? Desde nuestra posición teórica y política, el carácter relacional de la lectura, en tanto práctica cultural, demanda una construcción categorial no-opresiva de tipo analítica. Se concibe el derecho a la lectura mediante la creación de diversas categorías.

Categorías políticas específicas y contingentes que ayuden a pensar relacionalmente; con el objeto de subvertir las lógicas colonialistas, imperialistas y capitalistas que alojan en su centro de actividad la noción de justicia educativa y social e inclusión, contribuyendo a la imposición de categorías ahistóricas y esencialistas para emprender la búsqueda del sujeto al interior de la justicia y la inclusión. (Ocampo y López-Andrada, 2019, p. 88)

Las políticas y programas relacionados con la educación lectora, el fomento de la lectura y el uso de los espacios lectores se han constituido como un acto de absorción de los colectivos vulnerables a las mismas estructuras -escolares, sociales, ciudadanas, culturales y políticassometidas por la cultura dominante-usando la metáfora: inclusión a lo mismo-, con el propósito de que estos sean asimilados imperceptiblemente por dichos cuerpos de valores. A juicio de Mouffe (2007), esto podría explicarse debido a "una falta total de comprensión de aquello que está en juego en la política democrática y en la constitución de las identidades políticas y, como veremos, contribuye a exacerbar el potencial antagónico que existe en la sociedad" (p. 10). Así, uno de los equívocos de interpretación más frecuentes consistirá en asumir un individualismo que reconoce, en la multiplicidad y el pluralismo, una estrategia retórica de tipo subversiva, al tiempo que es incapaz de reconocer la naturaleza plural del mundo cultural y educativo, "debemos entender la singularidad como inextricablemente unida a la multiplicidad" (Bal, 2009, p. 59).

Las políticas de reconocimiento (Fraser y Honneth, 2006) e identidad (Fraser, 2000) en el contexto de las prácticas de educación lectora a través del prisma proporcionado por la justicia social asumen un proceso de individuación, fundamentalmente, articulado a través del problema ontológico que afecta a la comprensión de los grupos sociales descrita por Young (2002). Desde esta perspectiva, la noción de diferencia se convierte en un dispositivo de devaluación social, articula un significante equívoco que debilita la construcción de justicia social y escolar. En este marco, las diferencias son concebidas a través de sujetos y colectivos con identidades sociales y culturales diferentes, es decir, ausentes de reciprocidad. El problema ontológico de los grupos 
doi: http://doi.org/10.15359/ree.24-1.11

URL: http://www.una.ac.cr/educare

CORREO: educare@una.cr

sociales refleja un déficit metodológico significativo, específicamente, es incapaz de develar las condiciones de cooptación de la subjetividad y del análisis interseccional, respecto de los múltiples sistemas de desigualdad que convergen y se entrecruzan en las trayectorias sociales y escolares, y en los procesos de biografización de cada sujeto y colectividad. Sus debilidades de carácter metodológicas devienen en la proliferación de pautas de regulación cultural de carácter homogénea, es decir, apelan a la creación de justicia a través de la totalidad y la universalidad, omitiendo condiciones sociopolíticas que favorezcan la redistribución, el reconocimiento, el pluralismo y, ante todo, la multiplicidad.

De este modo, el análisis del derecho a la lectura en clave relacional articula una disposición analítica de carácter específica de saberes, formas metodológicas, vocabularios y concepciones ético-políticas, que interrogan la equivalencia analítica de identidades colectivas en niveles de reconocimiento (Young, 2005), cuyos ejes de análisis operan diferencialmente, respecto de las nociones de grupo social, ejes de desigualdad múltiple, política de la diferencia y emancipación social. La potencia analítica de los niveles de reconocimiento descritos por Fraser y Honneth (2006) permiten intervenir en los ejes de articulación de los programas de mediación y fomento de la lectura en poblaciones significadas como sujetos lectores precarios, analfabetos funcionales, colectivos vulnerables o en situación de desventaja social, y asegura herramientas críticas que permitan maximizar su experiencia de culturización.

El estudio del derecho a la lectura desde una perspectiva relacional articula una coyuntura específica de saberes, disciplinas, metodologías y formas de análisis en torno a la producción de diversos sistemas de desigualdad y dispositivos de arrastre que afectan la experiencia subjetiva de ciertos grupos al interior de los procesos de escolarización y su participación activa en la trama ciudadana y cultural. Todo ello exige crear prácticas lectoras de transformación -concebimos la transformación como aquella fuerza que disloca, nos gira hacia la creación de otros mundos-, es decir, cuya configuración fomenta el fortalecimiento de la ciudadanía y la justicia a través de la lectura y el discurso de lo Otro, concebido lo otro, como sistema de alteridad en potencia. La práctica de la lectura entendida como tarea hermenéutica se convierte en un objetivo crítico clave en el ensanchamiento de los marcos de desarrollo ciudadano. Como disposición específica de verdad, forja una singular forma de saber, en ella, se entrecruzan formas analíticas referidas al estudio de la justicia social, la creación de estrategias para la reducción y erradicación de las diversas expresiones del poder, la comprensión situada sobre las formas de regenerativas de la desigualdad, la opresión, la dominación, concebidas todas ellas, como sistemas de freno al autodesarrollo.

Es tarea crítica de las prácticas de educación lectora en el contexto de la multiplicidad de diferencias configurar un dispositivo de perturbación empática que, a juicio de Hite (2016), describe "aquello que nos incómoda, perturba, frustra, su constitución oscila entre la implicación y la ruptura, nos reformula de manera productiva" (p. 19). Sobre este particular, la investigadora norteamericana agrega que es "un terreno cognitivo y emocional que se mueve entre la 
implicación y la ruptura, la dinámica entre la transición y la recepción" (Hite, 2016, p. 19). ¿Qué imaginarios abre la lectura en el contexto de lo político?, ¿de qué manera es posible fortalecer la configuración de una conciencia política y solidaria a través del derecho a la lectura?

La lectura como praxis política opera en términos de un dispositivo de intermediación, favorece la conjunción de variados sistemas de razonamientos sobre los que se articulan la democracia y los derechos humanos. ¿A qué niveles de compromiso nos invita la lectura en tanto práctica social y cultural?, ¿qué distancias ideológicas se colocan al descubierto en la lucha por la inclusión y el aseguramiento de condiciones de justicia y mayores oportunidades culturales dirigidos a la multiplicidad de diferencias? La lectura, en tanto práctica cultural, constituye una posibilidad real de democratización y concientización. Se convierte en un espacio de encuentro, lo que exige analizar qué es lo que consigue cada persona lectora, mediadora o trabajadora cultural y autora, a través de la lectura, así como el tipo de denuncias que de ella se desprenden acerca de determinados problemas sociales. La lectura como acción crítica fomenta el diálogo en torno a la multiplicidad de significados desprendido de nociones, tales como, alteridad, encuentro, justicia, etc., intentando comprender cómo a través de cada uno de éstos conceptos es posible irrumpir nuestra cotidianeidad y marcos de valores.

¿Qué acciones colaboran en la formación de la conciencia política de la ciudadanía a través de la lectura? Sobre este particular, el sintagma perturbación empática constituye una herramienta clave, nos mueve hacia la búsqueda de diversas formas de entendimiento, develando la diversidad de consecuencias de la represión, la opresión y la dominación, entre otras. Su objetivo crítico clave consistirá, entonces, en develar las formas que guardan los sentidos de la vulnerabilidad, la injusticia, la inclusión y la multiplicidad y sus formas críticas en el mundo contemporáneo. La lectura en tanto praxis política y cultural, articulará un análisis crítico sobre los procesos de éticos, histórico-sociales y políticos, mediante la configuración de una disposición específica de disciplinas y conceptos. El sentido crítico de la lectura, en cuanto praxis política y cultural, deviene en "un proceso colectivo de procesar en un conjunto de espacios para cuestionarlos, entenderlos y sentirlos como lugares de negociación y creación de una solidaridad global" (Hite, 2016, p. 21).

Al concebir la lectura como dispositivo de creación de lo posible -acontecimiento-, sus tareas hermenéuticas no solo convergen en la lectura del mundo, sino, más bien, se convierten en una estrategia de recuperación de la memoria -desde ningún punto de vista se reduce a un simple sistema de evocación-, concebida como designación de un posicionamiento y localidad crítica, mediante la cual se rearticula y refuncionaliza el mundo y el lugar de inscripción de la singularidad de cada sujeto. Bajo esta denominación, la lectura se convierte en una espacialidad extensa y diversificada de la cultura, articula una multidireccionalidad de trayectorias analíticas, políticas y éticas en la comprensión del mundo. En tal caso, lo político de la lectura se materializa en torno a los siguientes propósitos: a) estrategia que agudiza un compromiso con el mundo 
doi: http://doi.org/10.15359/ree.24-1.11

URL: http://www.una.ac.cr/educare

CORREO: educare@una.cr

ideológico, b) dispositivo de creatividad, imaginación y recuperación de sustantivos críticos al servicio de la micropráctica -interacción cotidiana entre diversos agentes y fuerzas de modelamiento social-, c) construcción de imaginarios críticos y dispositivo de interrogación de la realidad. Concebida así, la lectura se convierte en ejercicio contingente, introduce en el examen de las prácticas críticas de los sujetos, de sus agencias y formas de irrupción en la realidad. La lectura, en tanto estrategia de intermediación, favorece la política del encuentro y el afianzamiento de la memoria. En tanto dispositivo didáctico, propende a la configuración de círculos de concientización a favor de la diferencia y la multiplicidad, y a la creación de otros mundos. Fortalece la esperanza y la solidaridad social.

Debido al efecto asimilacionista y compensatorio instaurado por las políticas educativas de inclusión, el ejercicio del derecho a la lectura deviene en la cristalización de un problema técnico, articulado en la incorporación de determinados colectivos ciudadanos a las mismas estructuras de escolarización, culturales, sociales y de participación política, con lo que se reafirma una política democrática neoliberal, sustentada en la metáfora de 'inclusión a lo mismo'. En tal caso, las desviaciones y obstrucciones en la implementación de la 'democracia liberal' a través de la racionalidad propuesta por la 'política de la diferencia' impulsada por Young (2002), devienen en la regeneración de prácticas ciudadanas ciegas, caracterizadas por la imposición de estereotipos históricamente anclados al interior de prácticas político-culturales y formaciones sociales específicas, las cuales constituyen un freno al avance plurizador ligado al ejercicio de la ciudadanía y la lectura. Al concebir la lectura como un problema eminentemente 'técnico' en las agendas contemporáneas de educación inclusiva, la proliferación de dispositivos estratégicos destinados al aseguramiento de condiciones de equidad y justicia cultural tiende a "restarle importancia a la relación históricamente elaborada entre lenguaje y poder, los educadores críticos no han logrado un discurso que articule cuestiones de identidad, lugar, pedagogía e historia con un lenguaje de visión y vida pública" (Giroux y McLaren, 1998, p. 18). Al constituir la educación inclusiva una teoría postcrítica, su centro crítico se articula a partir de la noción de 'multiplicidad de diferencias', sus preocupaciones políticas convergerán en torno a problemáticas que aborden "cómo el lenguaje se utiliza tanto para legitimar como para marginar diferentes posturas sobre un terna o cómo el conocimiento no sólo mistifica sino funciona para generar identidades, deseos y necesidades" (McLaren, 1998, p. 20).

\section{Lectura en la posmodernidad: Visiones de la alfabetización crítica y de la educación lectora}

El carácter diseminal de la práctica lectora, propiedad intrínseca de la postmodernidad (Lyotard, 1985; Vattimo, 1989), es concebida en términos foucaultianos como 'dispositivo', es decir, estrategia que integra un conjunto decididamente heterogéneo de discursos, disciplinas, objetos, métodos, proposiciones filosóficas, entre otras. Como tal, ha sido abordado por una multiplicidad de estudios y campos de conocimiento, entre los cuales destacan: Agamben 
(2011), Beuscart y Peerbaye (2006), Bussolini (2010), Deleuze (1990), Foucault (1985), García (2011). La lectura, concebida en términos de dispositivo, ofrece una comprensión metodológica en torno a las convergencias disciplinarias, metodológicas, objetuales, teóricas y discursivas que crean y garantizan su conocimiento.

La hibridación de prácticas (orales y escritas, de lectura y de escritura), y de formatos está ocupando paulatinamente un espacio propio de cohabitación en el presente. El desarrollo de la competencia lectora se articula en escenarios que van más allá de la institución educativa. Espacios novedosos que tienen que ver con el entretenimiento y el ocio, pero también con la creación de redes y espacios de sociabilidad.

Frecuentemente, los debates en torno a la dimensión política de la lectura reafirman su compromiso con el ejercicio de una ciudadanía activa, crítica y participativa. En otras palabras, refuerzan la condición democrática. Si bien es cierto, la lectura ha de ser concebida como la puerta de ingreso al ejercicio de la ciudadanía, es plausible, también, afirmar la necesidad de avanzar en la construcción del concepto de 'ciudadanía lectora', en tanto ofrezca la posibilidad de deconstruir las visiones dominantes sobre la condición democrática, que en ocasiones se tornan rígidas, acríticas y contribuyen a reforzar contextos democráticos de baja intensidad, es decir, cuya racionalidad queda sujeta a la performatividad de las múltiples expresiones del poder; restringiendo, con ello, la consolidación de una consciencia crítica, que a través de los procesos de alfabetización y educación lectora, permita poder decidir y comprometerse con los asuntos de su comunidad.

Más bien, al constituir una metáfora que ficcionaliza la realidad, retóricamente, otorga un cierto poder de transformación a través de la lectura, incapaz de forjar un compromiso reflexivo que vaya más allá de la titularidad de ciertos derechos. La condición democrática a través de la lectura se obtiene mediante la 'filosofía de la praxis' y del 'contra-poder', es decir, de sistemas de razonamientos que ayudan a entender cómo una cierta idea de progreso a través de la educación y el acceso a los bienes culturales es incapaz de transformar el conjunto de condiciones estructurales de vida de cada sujeto lector. Sobre este particular, la metáfora: 'la lectura es una puerta de ingreso al ejercicio ciudadano', se convierte en una estrategia clave del esencialismo liberal y, en ocasiones, se alinea con la noción de esencialismo estratégico propuesto por Spivak (1984).

Un proceso de educación lectora consciente en la búsqueda de nuevos sistemas intelectuales que permitan movilizar la condición democrática y devolver el poder a las personas se adscribirá a una política emancipadora de lectura, cuya articulación emerge desde estrategias de toma de conciencia. La toma de conciencia se convierte en una pieza angular en la creación de espacios de lectura, pues fortalece lo que anteriormente hemos denominado como 'estrategia-de- pensamiento-relacional' al analizar el funcionamiento de las principales 
doi: http://doi.org/10.15359/ree.24-1.11

URL: http://www.una.ac.cr/educare

CORREO: educare@una.cr

patologías sociales crónicas. El pensamiento relacional de naturaleza dinámica, holística e interactiva orienta su actividad a la comprensión analítica de la movilidad y performatividad de las relaciones estructurales que generan poblaciones excedentes.

Una política emancipatoria sobre educación lectora parte del reconocimiento de dos puntos de inflexión claves: a) la devaluación y violenciación de los modos de aproximación y construcción de la capacidad hermenéutica articulada por colectivos que por diversas razones no han compatibilizado con la gramática proporcionada por la cultura letrada dominante y b) el interés técnico de los programas de animación y fomento de la lectura desde una perspectiva de equidad y justicia cultural, los cuales tienden a resolver el problema, desde el centro de acción de las mismas estructuras del poder y de la exclusión, deviniendo en una suerte de incorporación de colectivos históricamente relegados de la gramática tradicional propuesta por la cultura letrada, al tiempo que los programas hacen convivir valores que apuestan por el pluralismo y la multiplicidad, mientras que sus condiciones programáticas tienden a reflejar acciones contrapuestas.

En esta estructura se espera que dichos colectivos sean absorbidos imperceptiblemente por los valores, pautas culturales e intereses proporcionados por la cultura dominante. Una política emancipatoria sobre educación lectora interroga profundamente la ontología que atraviesa al concepto de grupo social. Asimismo, se propone -inspirada en el pensamiento relacional- cristalizar una política que apunte a una revolución cultural. Para ello, toma como referencia los planteamientos de Young (2002) respecto de las estrategias de toma de consciencia, pues reconoce un sólido escenario didáctico para comprender cómo las nociones de 'opresión', 'injusticia', 'exclusión', 'dominación' -todas ellas, expresiones performativas del poder-, afectan y cruzan la experiencia de todos los colectivos ciudadanos.

De acuerdo con esto, una política emancipatoria sobre educación lectora inscribe su objetivo terminal en la cristalización de una revolución cultural, cuyo centro de articulación es precedido por las estrategias de toma de conciencia, cuyo legado se encuentra en diversos grupos del feminismo genealógico y contemporáneo. Las estrategias de toma de consciencia en Freire (1970) se conocen como 'círculos de reflexión', cuya potencia consiste en que la multiplicidad de singularidades dialogan e intercambian experiencias comunes -pensamiento relacional- en torno a la injusticia, la exclusión, la fustración, el desencanto y el sufrimiento social, encontrando puntos de captura (Lacan, 1989) entre cada uno de ellos. Si transferimos este recurso metodológico a la comprensión de los espacios escolares y sus comunidades, fácilmente podrán ser identificados los obstáculos complejos que hacen que la articulación de su tarea educativa no logre proporcionar destinos sociales más esperanzadores para cada estudiante. Facilita, de esta forma, el reconocimiento de los modos de opresión transversales que afectan a diversas personas, grupos sociales y comunidades educativas. 
La alfabetización crítica como construcción ideológica es el fundamento del proyecto emancipador que deviene en movimiento social. Cabe pararse a repensar una historia de la alfabetización que se ha caracterizado por la aprobación y conformidad con el discurso hegemónico (Gramsci, 1999), en la búsqueda del fortalecimiento de una categorización social que garantizase que "las personas situadas en la parte inferior de la jerarquía acepten los valores, normas y creencias de las élites, aunque hacerlo no contribuya a su beneficio particular ni al de su grupo" (Gee, 2005, p. 51). La fenomenología encarnada de los lectores se convierte en una herramienta de examinación crítica de la realidad, que permite demostrar cómo determinados colectivos y sus respectivos capitales culturales son restringidos en su potencia a una visión que los describe como insuficientes en sus capacidades, oportunidades, o incluso, en sus habilidades cognitivas, por el único hecho de proceder de determinadas latitudes del mundo, 0 bien, por pertenecer a sectores sociales que no gozan de los privilegios de la cultura económica dominante. Al deconstruir tales supuestos, observamos que gran parte de la población sería objeto de esta concepción en su trayectoria escolar y social.

\section{Representaciones del paradigma PISA}

Al abordar la construcción de representaciones de las prácticas lectoras, resulta de interés tener en cuenta elementos relacionados con la recepción y la circulación de resultados internacionales sobre competencia y comprensión lectora, cuyo modelo paradigmático es el Informe PISA (Programme for International Student Assessment) y su tratamiento en los medios de comunicación.

El criterio que determina la difusión de estos resultados, los verdaderos sectores beneficiados de estas evaluaciones internacionales externas, o el efecto que suscita en las representaciones de la lectura y en relación con los sujetos lectores en situación de aprendizaje, resulta, en ocasiones, borroso e impreciso; asimismo, serán preguntas pertinentes de cómo la articulación de significados excluye, en ocasiones, a los propios grupos protagonistas de estas prácticas lectoras (Bombini 2008).

El interés que han despertado en las últimas décadas estos estudios e informes de carácter internacional se asocia a lo siguiente:

La convicción generalizada de que la productividad económica futura de un país depende de los altos niveles de conocimientos y competencias en la población activa y de que mostrarán una mejor posición internacional aquellas naciones que tengan población con mayor nivel, especialmente en lectura, matemáticas y ciencias. (Martínez, 2006, p. 112) 
doi: http://doi.org/10.15359/ree.24-1.11

URL: http://www.una.ac.cr/educare

CORREO: educare@una.cr

La educación funciona, en este caso, como variable económica, como motor para el desarrollo y el crecimiento económico de los Estados. Se produce, pues, una subordinación a elementos de la mundialización económica y de la valorización capitalista manifestados en la competición por puntuar lo más alto posible en los rankings a través de la mejora de la "calidad" y "excelencia" educativa, terminología utilizada en este tipo de retórica completamente vaciada de significado (Fernández-González, 2015; Saura y Luengo, 2015). PISA acentúa el aprendizaje al margen del currículo escolar (Fernández-Cano, 2016), lo que en términos de evaluación imposibilita la capacidad de converger estos resultados al ámbito de las micropolíticas educativas de cada país (Prais, 2003). Por otro lado, las limitaciones metodológicas de PISA se extienden a la opacidad de la muestra, a la incorrecta enunciación de las hipótesis correlaciónales y a la cuestionable validez de los instrumentos de medida (Fernández-Cano, 2016).

Uno de los problemas más significativos que enfrentan las evaluaciones estandarizadas consiste en negar la singularidad que define, cualitativamente, el papel de la competencia lectora de cada aprendiente. En este sentido, se observa la coexistencia de un dispositivo de homogenización sobre los aspectos cognitivos implicados en el acto de leer. En este contexto, las evaluaciones de la 'comprensión lectora' -capacidad para captar lo más precisamente la intención de la autoría- y de la 'competencia lectora' -capacidad para utilizar la información en diversos contextos de actuación-, desconocen el papel del desempeño cognitivo que cada sujeto lector posee en relación con el acto de lectura. Adscribimos a la concepción de desempeño cognitivo como diversas maneras de demostrar lo aprendido, comprobamos que los formatos utilizados otorgan una visión estática de la real comprensión alcanzada por cada estudiante; de una manera u otra, el dispositivo metodológico empleado, arraigado en un ideal de universalidad que niega las diferencias intrínsecas del ser humano, solo es capaz de ofrecer una visión artificial acerca del desempeño lector y omite la multiplicidad de acciones propias de la estructura cognitiva de cada persona.

En este contexto, las dificultades de acceso y manipulación de la lectura tienden a regenerar el ideal esencialista para explicar sus problemáticas, cuyas acciones discursivas solapan los errores y contradicciones del formato escolar, atribuyendo que son problemáticas individuales propias de cada estudiante. En palabras de Young (2002), dichas contrariedades pueden explicarse mediante una creencia que resalta la naturaleza de lo esencialmente diferente, atribuyendo, de esta forma, un estatus de inferioridad a quienes no alcanzan los estándares esperados.

Para Young (2002), las políticas de la OCDE en relación con los sistemas de medición de las competencias lectoras solo insisten en reducir y cosificar el capital cultural diversificado y propio de la experiencia de la multiplicidad, a una media de lo común; constituyen una de múltiples estrategias que construyen como poco competentes -con lo que imponen la metáfora de Kaplan (2012) referida a buen y mal estudiantado- a aquellas comunidades y estudiantes que están por debajo de los indicadores y las puntuaciones legitimadas sociopolíticamente por cada nación. 
Es tarea de los centros educativos la creación de herramientas para deshacer las clasificaciones y expectativas que se esconden en la conciencia interpretativa de los resultados escolares, adquirir la forma de esquemas clasificatorios, y facilitar sus medios de distinción y categorización.

De esta forma, los sistemas de mediciones estandarizadas -cada vez menos oportunas-, al medir a todas las personas con criterios universales, articula una concepción dicotómica de tipo jerárquica acerca de la diferencia, del rendimiento escolar, de la cognición humana, de la pertinencia o no, de los sujetos educadores y de la valía social de las propias instituciones educativas. Todas estas manifestaciones no son otra cosa que una expresión de las ideologías objetivistas de la justicia social y educativa. En ella, los grupos devaluados solo son aquellos que obtienen bajos resultados, o bien son oprimidos por pertenecer a sectores con menos oportunidades culturales, medidos arbitrariamente por los marcos de valores hegemónicos de la cultura dominante, que sancionan o no aquello que es legítimo de ser considerado como una experiencia cultural válida. En esta posición, los grupos privilegiados, a juicio de Young (2002), se tornan neutros, mientras que los anteriores solo existen en un conjunto reducido de posibilidades.

Comúnmente, los resultados son empleados como círculos condenatorios de las comunidades educativas, con lo que se incrementa el estrés social y la devaluación cultural, a causa de no lograr ingresar en determinados rankins de mediación. Uno de los principales fracasos cognitivos en los que inquiere esta visión consiste en presentar un instrumento homogéneo para mediar el capital cultural e inyectado de una amplia multiplicidad de lectores y lectoras, y sostener, así, una visión del capital cultural también homogénea y relativista. Es imposible evaluar la calidad educativa desde una política sustentada en la universalidad y la homogeneidad, puesto que cada comunidad escolar inscribe su tarea educativa y formativa en condiciones histórico-culturales particulares. Por tanto, existe una multiplicidad de capitales culturales, cuya heterogeneidad jamás logrará ser percibida como algo inherente a la experiencia cultural, pues los criterios que sustentan dichas evaluaciones omiten este tipo de discusiones. Las evaluaciones estandarizadas deben constituir símbolos de esperanzas para las escuelas y no acciones de victimización y culpabilización, las cuales no son otra cosa que efectos propios del paternalismo y de una visión de educación e inclusión, alojada al interior del capitalismo. Un programa político, orientado a ampliar oportunidades y destinos sociales 'en' la lectura y 'a través' de esta, deberá, ante todo, mapear las complicidades imperceptibles de la gramática cultural con los intereses del colonialismo.

El concepto de ciudadanía lectora reafirma la necesidad de consolidar una representación cultural alternativa, esto es, proveer de instrumentos que permitan agilizar una discusión cultural politizada sobre aquello que vamos a entender como práctica lectora y sistemas de apropiación de esta en el mundo contemporáneo. De acuerdo con la historia de la conciencia, la inclusión sintetizaría sus principales objetivos de lucha; en ella, los grupos históricamente significados como despreciados, oprimidos, abyectos o minoritarios -que en sí mismos 
doi: http://doi.org/10.15359/ree.24-1.11

URL: http://www.una.ac.cr/educare

CORREO: educare@una.cr

son mayorías en el mundo- ponen en jaque las bases del imperialismo cultural, al reafirmar la necesidad de deconstruir sus marcos de valores y estrategias de operacionalización. La lectura es uno de sus principales síntomas. Hasta ahora, las políticas educativas, formación del profesorado y la investigación, por más inclusiva que se diga, o bien, por emplear un lenguaje que alberge a diversas colectividades, ha sido incapaz de subvertir, en lo más profundo de sus intervenciones, el significado opresivo de la diferencia asociado a diversos grupos, creando intervenciones absolutas y cerradas para asumir la alteridad en los diversos planos y propósitos del desarrollo social. En suma, coexisten valores, prácticas, posiciones epistémicas, discursos, agencias, instrumentos conceptuales y horizontes metodológicos y políticos que refuerzan imperceptiblemente un significado esencialista y opresivo sobre una de las propiedades intrínsecas más relevantes de la naturaleza humana: la diferencia.

\section{Consideraciones finales: Hacia una lectura contrahegemónica del mundo}

Recurriendo a los aportes contrahegemónicos de la teoría crítica latinoamericanista, se integran los mecanismos de colonización cultural, subjetiva, política, cognitiva y pedagógica para comprender cómo los dispositivos de dominación cultural, inscritos en un marco de valores determinados (al interior de una matriz de poder colonial), crean y garantizan condiciones epistémicas (ya sea por reciclajes o bien por sistemas de hibridación del saber) con ciertas ficciones políticas e ideológicas que contribuyen a dar continuidad al sistema neoliberal, pues omiten la comprensión de ciertas lógicas ocultas que permitirían subvertir sus efectos deshumanizantes; al tiempo que crean y producen poblaciones excedentes, sin cuestionar los dispositivos que al interior de las estructuras sociales, culturales y políticas arrastran a determinados colectivos a los márgenes del derecho a la educación.

La producción de temas claves en los programas de animación a la lectura deben recoger los saberes y las prácticas críticas que definen la acción cultural de los colectivos marginalizados, sin perjuicio de anular sus saberes de base. En tal caso, la agenda micropolítica posible, en el campo de la lectura como derecho, convergerá los patrones de resistencia del devenir minoritario ante los mecanismos de institucionalización y performatividad de los valores culturales e intelectuales dominantes que intentan posicionarse por medio de la animación a la lectura. Por otra parte, sus lineamientos de trabajo versarán sobre la ruptura de los diversos mecanismos que conforman el conjunto de colonizaciones epistémicas, impuestas mediante las estrategias de reproducción del mundo social, cultural y ciudadano (Guattari y Rolnik, 2006).

El derecho a la lectura desde una perspectiva de educación inclusiva invita a promover una arquitectura cultural, política y educativa de tipo heterotópica, constituida mediante un sólido análisis sobre los patrones institucionales del poder. Esto es, crear y fortalecer un proyecto político otro en materia de promoción de la lectura. ¿Cómo fomentar la toma de consciencia 
a través de la lectura?, ¿cómo crear a través de la lectura una praxis transformadora? Cada una de estas interrogantes plantea el desafío de forjar una conciencia intencional hacia el mundo, fomentando la acción y la reflexión en clave transformacional, específicamente, en la realidad que habita y co-construye cada sujeto lector. La lectura tiene por objetivo esencial fortalecer la presencia del ser en el mundo, esto es, cristalizar una praxis liberadora a través de ella. Sin duda alguna, este constituye uno de los nudos críticos de la escolarización, la mediación cultural y el derecho a la lectura. Recuperando los aportes de Freire (1997), la cristalización de una praxis liberadora a través de la lectura ha de ayudar a comprender dialécticamente, a reconocer el mundo que habitamos y las posibilidades de cada agente en su transformación. De modo que "la concientización implica la constante clarificación de lo que queda escondido dentro de nosotros mientras nos movemos en el mundo, no necesariamente tomándola como objeto de nuestra reflexión crítica" (Freire, 1983, p. 89).

La lectura como praxis de liberación se propone favorecer la actividad heurística de la conciencia, reconociendo, de este modo, que la transformación de la realidad solo es posible en la medida que se transforma la conciencia. La lectura se convierte en una condicionante del devenir. Implícitamente, la lectura en tanto sistema de liberación de la conciencia insiste en la comprensión crítica de los significados que de ella emergen. Los significados de la comprensión crítica pueden ser estudiados en relación con la contribución de la Escuela de Frankfurt y la teoría de Paulo Freire. La primera, rescata la crítica inmanente de la realidad que vivimos, estructurada a partir de múltiples desigualdades -ejes trans-históricos en la historia de la conciencia de la humanidad-. Lo sustantivo de esta corriente promueve el desarrollo de la lectura en tanto herramienta para forjar una consciencia crítica y proponer alternativas que sean más justas para el desarrollo de la lectura y de los programas de animación. La segunda, por su parte, penetra lo social con un sentido crítico y político; a través de esta visión se hace necesario superar el efecto paternalista que generan los programas de lectura a grupos significados como vulnerables. Sobre este particular, Freire (1983) agrega:

Leer no es una destreza cognitiva independiente de personas y contextos, sino una herramienta para actuar en la sociedad, un instrumento para mejorar las condiciones de vida del aprendiz. No leemos textos ni comprendemos significados neutros; leemos discursos de nuestro entorno y comprendemos datos que nos permiten interactuar y modificar nuestra vida. Leer un discurso es también leer el mundo en el que vivimos. (p. 145)

De tal manera que la potencia de la lectura, en tanto arma de penetración y dominación pluralista del mundo, es la razón por la cual la constitución de una trama ciudadana y escolar inscribirá sus objetivos en una ontología pluralista del ser, de la calidad de la enseñanza, de su espacialidad política y epistémica. 
doi: http://doi.org/10.15359/ree.24-1.11

URL: http://www.una.ac.cr/educare

CORREO: educare@una.cr

\section{Referencias}

Agamben, G. (2011). ¿Qué es un dispositivo? Sociológica México, 26(73), 249-264. Recuperado de http://ayp.unia.es/r08/IMG/pdf/agamben-dispositivo.pdf

Apple, M. W. (1986). Maestros y textos. Una economía política de relaciones de clase y sexo en educación. Barcelona: Paidós.

Bahloul, J. (2002). Lecturas precarias: Estudio sociológico sobre los" poco lectores". México: Fondo de Cultura Económica.

Bal, M. (2009). Arte para lo político. Revista Estudios Visuales, 7, 40-65.

Beuscart, J.-S. y Peerbaye, A. (2006). Histoires de dispositifs. Terrains \& Travaux, 2(11), 3-15. Recuperado de https://www.cairn.info/revue-terrains-et-travaux-2006-2-page-3. htm?contenu=resume

Black, M. (1963). Models and Metaphors. Studies in language and philosopy. Ithaca, New York: Cornell University Press.

Bombini, G. (2008). La lectura como política educativa. Revista iberoamericana de educación, 46, 19-35. doi: https://doi.org/10.35362/rie460714

Bourdieu, P., Chamboredon, J.-C- y Passeron, J.-C. (1994). El oficio de sociólogo. Presupuestos epistemológicos. Madrid: Siglo XXI.

Brah, A. (2011). Cartografías de la diáspora. Identidades en cuestión. Madrid: Traficante de Sueños.

Bussolini, J. (2010). What is a Dispositive? Foucault Studies, 10, 85-107. doi: https://doi. org/10.22439/fs.v0i10.3120

Chartier, R. (2002). Prácticas de la lectura. Buenos Aires: Plural editores.

de Mussy, L. G. y Valderrama, M. (2009). Historiografía postmoderna: Conceptos, figuras y manifiestos. Santiago: RIL Editores.

de Sousa Santos, B. (2009). Una epistemología del sur: La reinvención del conocimiento y la emancipación social. México: Siglo XXI.

de Sousa Santos, B. (2010). Descolonizar el saber, reinventar el poder. Montevideo-Uruguay: Ediciones Trilce.

Deleuze, G. (1969). Lógica del sentido. Buenos Aires: Siglo XXI Editores.

Deleuze, G. (1990). ¿Qué es un dispositivo? En E. Balbier y G. Deleuze (Autores), Michel Foucault, filósofo (pp. 155-163). Barcelona: Gedisa. 
Esperón, J. P. E. (2014). El acontecimiento y la diferencia en la filosofía de Gilles Deleuze. Nuevo pensamiento. Revista de Filosofía, 4(4), 286-314. Recuperado de https://dialnet.unirioja.es/ servlet/articulo?codigo $=5513801$

Fernández-Cano, A. (2016). Una crítica metodológica a las evaluaciones PISA. Revista Electrónica de Investigación y Evaluación Educativa, RELIEVE, 22(1), 1-17. doi: https://doi.org/10.7203/ relieve.22.1.8806

Fernández-González, N. (2015). PISA como instrumento de legitimación de la reforma de la LOMCE. Bordón. Revista de pedagogía, 67(1), 165-178. doi: https://doi.org/10.13042/ Bordon.2015.67111

Foucault, M. (1973). La verdad y las formas jurídicas. Barcelona: Gedisa.

Foucault, M. (1985). Saber y verdad. Madrid: Editorial Piqueta.

Fraser, N. (2000). Rethinking recognition. New left review, 3, 107-29. Recuperado de https:// newleftreview.org/issues/ll3/articles/nancy-fraser-rethinking-recognition

Fraser, N. y Honneth, A. (2006). ¿Redistribución o reconocimiento?: Un debate político-filosófico. Fundación Paideia Galiza.

Freire, P. (1970). La educación como práctica de libertad. México: Siglo XXI.

Freire, P. (1983). Pedagogía de la autonomía. Saberes necesarios para la práctica educativa. México: Siglo XXI.

Freire, P. (1997). Política y educación. México: Siglo XXI.

García,L.(2011).¿Quéesun dispositivo?:Foucault,Deleuze,Agamben.AParteRei:revistadefilosofía, 74, 1-8. Recuperado de https://dialnet.unirioja.es/servlet/articulo?codigo=3644313

Gee, J. P. (2005). La ideología en los discursos. Madrid: Morata.

Giroux, H. y McLaren, P. (1998). Sociedad, cultura y educación. Madrid: Editorial: Miñó y Dávila Editores.

Gramsci, A. (1999). Cuadernos de la cárcel (Tomo 2). México: Ediciones Era.

Guattari, F. y Rolnik, S. (2006). Micropolítica: Cartografías del deseo. Madrid: Traficantes de Sueños.

Gutiérrez, A. (2009). El estudio de las prácticas y las representaciones sociales de la lectura: Génesis y el estado del arte. Anales de Documentación, 12, 53-67. ecuperado de https:// revistas.um.es/analesdoc/article/view/70241/67711

Hite, K. (2016). Pedagogía crítica, perturbación empática, y la política de los encuentros en los 
doi: http://doi.org/10.15359/ree.24-1.11

URL: http://www.una.ac.cr/educare

CORREO: educare@una.cr

espacios de la memoria en Chile (Colección Signos de la Memoria). Santiago: Museo de la Memoria y los Derechos Humanos.

hooks, B. (2017). El feminismo es para todo el mundo. Madrid: Traficante de Sueños.

Kaplan, C. V. (2012). Buenos y malos alumnos. Descripciones que predecen. Buenos Aires: Aique.

Lacan, J. (1989). Escritos. México: Siglo XXI.

Lahire, B. (2004). Sociología de la lectura: Del consumo cultural a las formas de la experiencia literaria. Barcelona: Gedisa.

Lakoff, G. y Johnson, M. (2009). Metáforas de la vida cotidiana. Madrid: Ediciones Cátedra.

Lyotard, J.-F. (1985). La posmodernidad (Explicada a los niños). Barcelona: Gedisa.

Martínez, R. (2006). La metodología de los estudios PISA. Revista de Educación, Extraordinario, 111-129. Recuperado de http://www.revistaeducacion.mec.es/re2006/re2006.pdf

McLaren, P. (1998). Multiculturalismo revolucionario: Pedagogías de disensión para el nuevo milenio. México: Siglo XXI.

Mouffe, C. (2007). En torno a lo político. México: FCE.

Ocampo, A. y López-Andrada, C. (2019). Lecturas de la multiplicidad: Para una articulación del derecho a la lectura en clave relacional. Pedagogía Social. Revista Interuniversitaria, 33, 8192. doi: https://doi.org/10.7179/PSRI 2019.33.06

Prais, S. J. (2003). Cautions on OECD's recent educational survey (PISA). Oxford Review of Education, 29(2), 139-163. doi: https://doi.org/10.1080/0305498032000080657

Ricoeur, P. (2001). La metáfora viva. Madrid: Ediciones Cristiandad.

Rizvi, F. y Lingard, B. (2009). Globalizing education policy. New York: Routledge. doi: https://doi. org/10.4324/9780203867396

Rockwell, E. (2001). La lectura como práctica cultural: Conceptos para el estudio de los libros escolares. Educação e Pesquisa, 27(1), 11-26. doi: http://dx.doi.org/10.1590/S1517$\underline{97022001000100002}$

Saura, G. y Luengo J. (2015). Política global más allá de lo nacional. Reforma educativa (LOMCE) y el régimen de estandarización (OECD). Bordón. Revista de Pedagogía, 67(1), 135-148. doi: https://doi.org/10.13042/Bordon.2015.67109 
doi: http://doi.org/10.15359/ree.24-1.11

URL: http://www.una.ac.cr/educare

Silva, R. (2003). La lectura: Una práctica cultural. Debate entre Pierre Bourdieu y Roger Chartier. Revista Sociedad y Economía, 4, 161-175. Recuperado de http://www.redalyc.org/articulo. oa?id=99617936017

Spivak, G. (1984). El desplazamiento y el discurso de la mujer. Debate Feminista, 5(9), 150-82.

Taylor, S., Rizvi, F., Lingard, B. y Henry, M. (1997). Educational policy and the politics of change. Oxon: Psychology Press.

Vattimo, G. (1989). El sujeto y la máscara. Nietzsche y el problema de la liberación. Barcelona: Ediciones Península.

Young, I. M. (2002). La justicia y la política de la diferencia. Valencia: Cátedra.

Young, I. M. (2005). On female body experience: "Throwing like a girl and other essays. Oxford: Oxford University Press. doi: https://doi.org/10.1093/0195161920.001.0001

Žižek, S. (2014). Acontecimiento. Ciudad de México: Sexto Piso. 